\title{
TRICHOPILIA X RAMONENSIS (ORCHIDACEAE), UN HÍBRIDO NATURAL DE COSTA RICA
}

\author{
CARlos O. Morales
}

\author{
Escuela de Biología, Universidad de Costa Rica. 2060 San José, Costa Rica \\ Jardín Botánico Lankester. Apdo. 1031-7050 Cartago, Costa Rica
}

\begin{abstract}
The natural hybrid Trichopilia $\times$ ramonensis (T. marginata $\times$ T. suavis) from the San Ramón region of Costa Rica is here described and illustrated. The name of this hybrid was used for the first time in 1992, nevertheless it has so far not been validly published.

RESUMEN. Se describe e ilustra el híbrido natural Trichopilia $\mathrm{x}$ ramonensis (T. marginata $\mathrm{x}$ T. suavis) de la región de San Ramón, Costa Rica. El nombre de este híbrido se usó por primera vez en 1992; sin embargo, hasta ahora no se ha publicado válidamente.
\end{abstract}

Palabras Clave / Key wORds: Trichopilia marginata, Trichopilia suavis, Trichopilia x ramonensis, híbridos naturales, Orchidaceae, Costa Rica.

El género neotropical Trichopilia Lindl. (Orchidaceae) se distribuye desde México y Cuba hasta el sur de Brasil y posee unas 30 especies (Horich 1996, Mora-Retana 1999, Bock \& Gruß 2000). Garay (1972) ubica el género en la subtribu Trichopiliinae, mientras que Dressler \& Williams (1970) y Dressler (1993b) lo hacen en Oncidiinae. Estudios recientes de ADN (Williams et al. 2001) sugieren que este género conforma un grupo aislado entre los táxones basales de Oncidiinae. En Mesoamérica se conocen entre 12 y 15 especies; seis de éstas habitan en Costa Rica (Mora-Retana 1999, Pupulin 2002). No obstante, ya se tienen evidencias de que en este país existen otros táxones de Trichopilia que rara vez han sido vistos o se han confundido con especies ya descritas (R.L. Dressler, F. Pupulin, com. pers. 2001). En general, este taxon es difícil; así lo reconocen distinguidos estudiosos de las orquídeas, como Horich (1996) y Dressler (1993a, 2001).

Trichopilia es, sin duda, uno de los géneros más atractivos de las orquídeas centroamericanas. Son plantas mayormente epífitas que habitan en bosques lluviosos de bajuras, así como en bosques húmedos de altitudes medias. Los pseudobulbos crecen densamente agrupados, son aplanados, subovados a oblongos y cada uno termina en una sola hoja. Las flores son a menudo aromáticas, de coloración variada, con morfología en general similar a la de Cattleya. El labelo es tubiforme o infundibuliforme, en algunas especies abierto y extendido en la parte distal.

En bosques del cantón de San Ramón, Alajuela, en la Cordillera de Tilarán, Costa Rica, se han hallado plantas con características intermedias entre las de $T$. marginata Henfr. (s.l.) y T. suavis Lindl., con flores relativamente grandes, de labelo roseo-púrpura, extendido y ondulado. Según comunicación del finado Joaquín García con Clarence K. Horich (1996), ya en el siglo XIX, hace 105 a 110 años, Richard Pfau observó plantas similares cerca del poblado de San Ramón, y el mismo Horich (loc. cit.: 179) lo hizo por ahí de 1973 cerca de La Balsa de San Ramón. La existencia de un híbrido natural de Trichopilia fue comunicada por Dressler (1993a) y Mora-Retana (1999). En enero de 1993 Horich envió semillas maduras a Alemania; éstas germinaron en tres semanas y las plantas florecieron siete años después en Bad Gandersheim, Baja Sajonia (Lucke 2000). Mora-Retana \& García (1992) anotan un nombre inédito para este taxon: "Trichopilia $\mathrm{x}$ ramonensis $\mathrm{J}$. García \& Mora-Retana (nat. hyb.), ined.”. Sin embargo, no existe una publicación válida, aun cuando plantas de este híbrido se han reproducido por semillas y han florecido al menos en Costa Rica, Alemania y Estados Unidos de Norteamérica. El híbrido artificial ha sido llamado Trichopilia $\mathrm{x}$ Charles (Dressler, com. pers. 2001). 
Trichopilia x ramonensis J. García \& Mora-Ret. ex C.O. Morales, nothosp. nova

FIG. 1

HOLOTIPO: Costa Rica. Alajuela; cantón San Ramón, distrito San Rafael. Berlín. $10^{\circ} 03^{\prime} \mathrm{N}$, $84^{\circ} 28^{\prime}$ O. Leg. Luis Acosta s.n. Floreció en marzo de 1991. USJ-57879 (en líquido).

Nothospecies nova hic descripta, sed multos annos ab egregiis orchideologis nota, apud J. García et Mora-Retana in anno 1992 iam citata sed adhuc non descripta. Epiphyta parva, pseudobulbis dense aggregatis, elongatis, $6-11 \mathrm{~cm}$ longis, $1,7-2,1 \mathrm{~cm}$ latis, plus minusve rectangulatis, complanatis, interdum falcatis. Foliis elliptico-lanceolatis, petiolo $0,5-2,0 \mathrm{~cm}$ longo, lamina 12-24 cm longa, 3,5-6,9 $\mathrm{cm}$ lata. Inflorescentia brevis, saepe 1 vel 3 (5) floribus. Sepalis petalisque rubriusculis, sepalis lateralibus ad basim 1,0-1,5 cm connatis; labello roseo-purpureo, inter Trichopiliam marginatam et $\mathrm{T}$. suavem intermedie structurato, $6,1-7,5 \mathrm{~cm}$ longo, 4,7-5,8 cm lato [complanato disposito], conspicue venato, ad apicem ampliato, profunde emarginato et obscure tetralobato, marginibus valde undulatis simul irregulatis; columna erecta, 2,8-3,1 cm longa, ad basim 1,0-1,5 cm cum labello connata; clinandrio supra anthera conspicue laciniato. Fructum non vidi.

Epífita con pseudobulbos densamente agrupados, alargados, 6-11 x 1,7-2,1 (2,5) cm, un poco más anchos cerca de la base, de forma más o menos rectangular, con bordes laterales casi paralelos, aplanados, a veces falcados. Hojas elíptico-lanceoladas, pecíolo $0,5-2 \mathrm{~cm}$ de largo, lámina $12-24 \mathrm{~cm}$ de largo, 3,5-6,9 cm de ancho máximo. Inflorescencia un racimo corto, generalmente arqueado, a veces colgante, surgiendo de la base de un pseudobulbo nuevo; con el raquis liso, glabro, levemente aplanado dorsiventralmente, de 3 a $5 \mathrm{~mm}$ de diámetro, entrenudos de 0,6 a 2,5 (3) cm de largo, entrenudo terminal reducido, a veces con una bráctea estéril. Brácteas florales ovado-lanceoladas, agudas, más anchas en la base, 1,8 cm largo, 1,2-1,4 cm de ancho máximo, grises, papiráceas, con puntos y manchas marrón claro. Pedicelo levemente curvo hasta doblado en hoz, 1,3 a $1,5 \mathrm{~cm}$ de largo. Flores generalmente 1 a 3 (5); sépalos y pétalos pardo-rojizos, labelo roseo-púrpura; ovario 2,7-2,8 cm de largo, sulcado; sépalo dorsal 5,7-6,6 x 1,1-1,6 cm, lanceolado; sépalos laterales 5,3-7,1 x 1,0-1,3 cm, lanceolados, connados 1,0-1,5 $\mathrm{cm}$ en la base, a menudo retrorsos en la parte media, con el haz ligeramente acanalado en el tercio proxi$\mathrm{mal}$; pétalos 5,2-6,7 x 1,1-1,5 cm, oblongos, ligeramente fusiformes, agudos a apiculados; labelo 6,4-7,5 $\mathrm{cm}$ de largo, 5,3-5,8 $\mathrm{cm}$ de ancho máximo [siendo extendido y ligeramente aplanado], formando un tubo ensanchado, abierto y extendido hacia el ápice, de forma intermedia entre T. marginata y $T$. suavis, envolviendo la columna, profundamente emarginado en el ápice y oscura e irregularmente tetralobado en la parte distal, con bordes muy ondulados e irregulares, lóbulos distales 2,2-2,8 x 1,1-2,3 cm, venación longitudinal conspicua, callo simple: una quilla estrecha elevada en el centro del labelo hasta ca. $0,5 \mathrm{~cm}$ más arriba de la columna; columna 2,8-3,1 cm de largo (hasta la antera), 0,4-0,5 cm de diámetro, recta, paralela a la base estrecha del labelo, ventralmente fusionada 1,0-1,5 cm con la base del labelo; clinandrio prominente, laminar, finamente laciniado, de hasta $0,8 \mathrm{~cm}$ sobre la antera y rodeándola; antera $0,5 \mathrm{~cm}$ de largo, $0,35 \mathrm{~cm}$ de ancho, ca. $0,30 \mathrm{~cm}$ de alto; polinios 2 , cada uno $2,5 \times$ ca. $1,5 \mathrm{~mm}$.

PARAtipos: Costa Rica. Alajuela: San Ramón. Cataratas. Leg. Luis Acosta s.n. 19 de marzo de 1992. USJ-44878 (material seco, piezas florales extendidas). "Trichopilia cf. ramonensis (Híbrido natural). Tiene caracteres intermedios entre T. marginata y $T$. suavis, sobre todo en el labelo" (det. Joaquín García \& Dora E. Mora). Alajuela: San Ramón [sin localidad exacta]. Leg. Luis Acosta s.n. Febrero de 1987. Floreció en cultivo, marzo de 1990. USJ31985 (material seco, un pseudobulbo, una hoja y una inflorescencia con tres flores). "Híbrido natural. Plantas con pseudobulbos alargados, con hojas elíptico-lanceoladas, anchas. Flores en racimo de 3-5, blanco-rosadas, con puntos y manchas rosado oscuro".

Material adicional visto: Costa Rica. Alajuela: San Ramón [sin localidad exacta]. Leg. desconocido. Floreció en enero de 2002, Jardín Botánico Lankester, Cartago, $1350 \mathrm{~m}$ (JBL \# 33). Planta dibujada, Fig. 1A.

"Híbrido artificial. Cruce hecho por Claudio Salas. Floreció en marzo de 1991". USJ-57881 (en líquido).

Este híbrido natural se reconoce por sus pseudobulbos alargados y estrechos, inflorescencias cortas, arqueadas, con 1 a 5 flores, con el labelo roseo-púrpura, ensanchado y abierto hacia el ápice, profundamente emarginado, fuerte e irregularmente ondulado y oscuramente tetralobado en la parte distal. Una variante de T. marginata s.l. con labelo púrpura ha sido confundida con el híbrido (por ejemplo, USJ-57902, en líquido, de la Reserva Biológica Alberto Brenes, San Ramón, Alajuela), pero las flores del híbrido son 


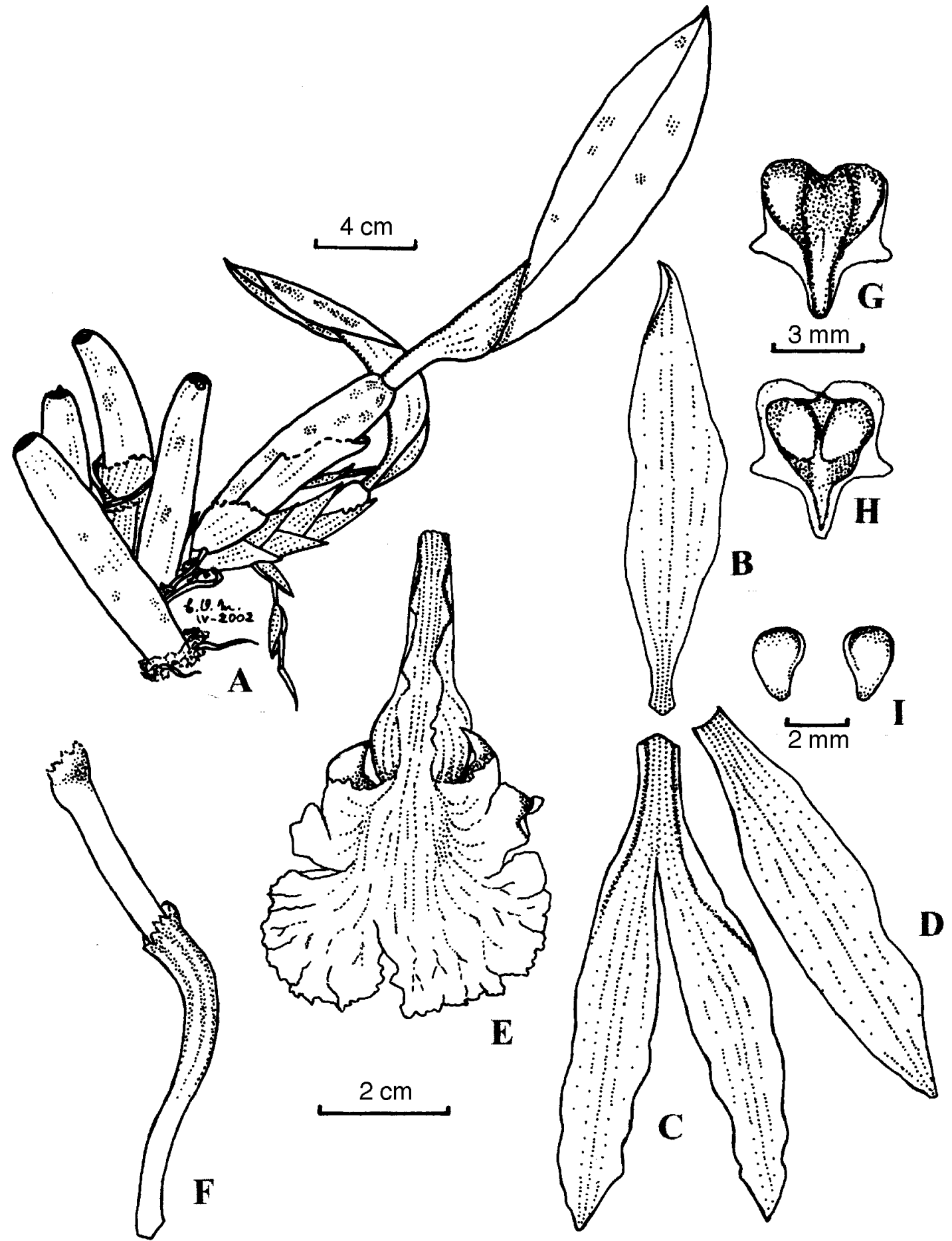

Figura 1. Trichopilia $\times$ ramonensis J. García \&Mora-Ret. ex C.O. Morales. A. Hábito; planta con restos de dos inflorescencias. B. Sépalo dorsal. C. Sépalos laterales. D. Pétalo. E. Labelo (algo extendido y aplanado). F. Columna con pedicelo (N.B. clinandrio incompleto). G. Antera, vista dorsal. H. Antera, vista ventral. I. Polinios. A: Dibujo del autor; planta del Jardín Botánico Lankester. B-I: Dibujos del holotipo (USJ), por Marcia González Garay. 
mucho más grandes y voluminosas, con el labelo más extendido y ondulado en la parte distal. Los pseudobulbos son morfológicamente muy similares en el híbrido y en $T$. marginata, pero en esta especie a menudo son mucho más largos que en el híbrido.

ILUSTRACIONES: Lucke (2000) y Bock \& Gruß (2000) ofrecen excelentes fotos en colores del híbrido y de los progenitores. En Horich (1996) se halla una fotografía del híbrido en blanco y negro.

Etimología: El epíteto latinizado ramonensis (español: ramonense) es el gentilicio que se refiere a San Ramón, el cantón donde se ha hallado el híbrido natural.

Las flores observadas y medidas muestran notables variaciones de tamaño. Una flor de un cruce artificial (C. Salas s.n., USJ, en líquido), que también fue medida detalladamente, exhibe un tamaño de piezas florales menor que en el holotipo; sin embargo, es fácil predecir que en híbridos artificiales mantenidos en óptimas condiciones de cultivo las flores serán más grandes que en plantas silvestres. Es probable que la variación en tamaño dependa no sólo del ambiente, sino también de la especie en la que se formó la cápsula. Probablemente, las flores son más grandes cuando la cápsula se formó en T. suavis, cuyo labelo es más voluminoso que el de T. marginata. En el híbrido, a menudo el labelo posee el borde blanco, lo cual también, al parecer, depende del origen de la cápsula (R.L. Dressler, comun. pers. 2002). En el campo, es probable la aparición de especímenes con sépalos laterales libres o unidos sólo por unos milímetros, tal como se observa en el híbrido artificial mencionado. Además, el taxon que, en sentido amplio, conocemos como T. marginata es notablemente variable, sobre todo en el color de las flores, lo que seguramente determina cierto grado de variabilidad en el híbrido. Los ejemplares secos de herbario muestran piezas florales notablemente reducidas de tamaño respecto a ejemplares preservados en alcohol o formalina. Por ello, todas las mediciones de órganos vegetativos y piezas florales de la descripción corresponden a ejemplares vivos o preservados en líquido.

DisTRIBUCIÓN Y ECOLOGÍA: Horich (1996: 182) sitúa el híbrido entre Ángeles Norte y el río San Lorenzo, cantón de San Ramón, a altitudes entre 900 y 1100 m. Ahora sabemos que la distribución es más amplia. Trichopilia $\mathrm{x}$ ramonensis habita en áreas de bosque tropical húmedo y premontano húmedo, entre 800 y
1100 m de altitud, en la Cordillera de Tilarán incluyendo la Reserva Biológica Alberto Brenes, en San Ramón, puesto que allí se han recolectado las dos especies progenitoras (ejemplares en CR y USJ). También es probable la presencia de este híbrido en la zona montañosa de Monteverde, Puntarenas, que colinda con la Reserva Biológica Alberto Brenes.

Ciertas plantas procedentes de algún lugar del cantón de Pérez Zeledón, zona sur de Costa Rica, cultivadas en el Jardín Botánico Lankester, son muy similares a las de $T . \times$ ramonensis, tanto vegetativamente como respecto a color y morfología floral. Sin embargo, las pocas flores de esas plantas que he visto son algo más pequeñas, el labelo es menos ondulado y tiene lóbulos mejor definidos que en las plantas de San Ramón. En Bock \& Gruß (2000: 758) la foto 2, determinada como Trichopilia marginata 'Wössen', muestra flores con labelo púrpura muy similares a las de Pérez Zeledón. Por cortesía de R.L. Dressler (comun. pers., abril de 2002) he visto la foto de una planta florecida de Panamá que, casi con seguridad, es T. x ramonensis. En Die Orchidee 43(6): 52 (Orchideenbewertung 1991), 1992, aparece una fotografía en colores determinada como "Trichopilia elegans 'Mariechen' SM(B) / D.O.G.”, que muestra una similitud extraordinaria con el híbrido aquí descrito. El nombre "T. elegans" no aparece válidamente publicado. Es necesario revisar detalladamente el material del sur de Costa Rica y de Panamá. Muy probablemente, pronto se revelará que el ámbito de distribución del híbrido natural es mucho mayor que el conocido hasta ahora. Teóricamente, el híbrido podría hallarse en todas las zonas donde coinciden $T$. marginata y T. suavis (Costa Rica y Panamá, entre 800 y 1200 m de elevación, aproximadamente; $c f$. Mora-Retana \& Atwood 1992, pero aparentemente no existen recolectas de ninguna de las dos especies en Colombia). No obstante, las poblaciones silvestres de los progenitores han desaparecido o han sido fuertemente diezmadas debido a la destrucción de grandes áreas boscosas y a la recolecta ilegal de orquídeas con fines comerciales. En la actualidad, es casi imposible hallar estas especies y el híbrido de ambas en los mismos sitios sin protección estatal donde fueron observados por Pfau, Brenes, Horich y Mora-Retana. Aunque la época de floración de ambas especies se traslapa (Mora-Retana 1999), no sabemos casi nada sobre las condiciones microambientales que favorecen la hibridación natural y el crecimiento de las plántulas. 
AgRadecimientos: Agradezco sinceramente las sugerencias y adiciones de Mario A. Blanco (USJ, FLAS), Franco Pupulin (Jard. Bot. Lankester) y Robert L. Dressler (FLAS), que mejoraron sustancialmente el texto. También agradezco a Marcia González las ilustraciones del holotipo. Aquí se honra la memoria de Joaquín B. García (1944-2001, vide Lankesteriana 3), quien queda además inmortalizado en Prosthechea joaquingarciana Pupulin [Selbyana 22(1): 19, fig. 3. 2001] y de Dora Emilia Mora (1940-2001, vide Lankesteriana 2). También recordamos a Clarence Klaus Horich (1930-1994), cuyo esfuerzo, así como el de otros naturalistas y horticultores alemanes, nos permite hoy conocer mejor la flora orquidácea de Costa Rica.

\section{LITERATURA CITADA}

Bock, Irene \& Gruß, O. 2000. Trichopilia Lindley, Introd. Nat. Syst. Ed. II: 446, 1836. Orchidee (Hamburg) 51(6): 758-759.

Dressler, R.L. 1993a. Field guide to the orchids of Costa Rica and Panama. Ithaca and London, Comstock Publishing Associates/Cornell University Press. 374 p.

Dressler, R.L. 1993b. Phylogeny and classification of the Orchid Family. Portland, Oregon, Dioscorides Press. $314 \mathrm{p}$.

Dressler, R.L. 2001. Mesoamerican orchid novelties: 5. Oncidiinae. Selbyana 22(1): 9-13.
Dressler, R.L. \& Williams, N.H. 1970. An overlooked genus in the Oncidiinae. Amer. Orch. Soc. Bull. 39(11): 988.

Garay, L.A. 1972. Notas sobre la Alianza Trichopilia. Orquideología 7(4): 191.

Horich, C.K. 1996. Schöne und seltene Trichopilia-Arten von Zentralamerika. Orchidee (Hamburg) 47(4): 177184.

Lucke, E. 2000. Aussaat und Blüte von Trichopilia x ramonensis. Orchidee (Hamburg) 51(4): 443-445.

Mora-Retana, Dora E. 1999. Trichopilia Lindl. In: Atwood, J.T. \& Mora-Retana, Dora E. Orchidaceae: Tribe Maxillarieae: Subtribes Maxillariinae and Oncidiinae. In: Burger, W. (ed.). Flora Costaricensis. Fieldiana, Bot. n.s. 40: 169-172.

Mora-Retana, Dora E. \& Atwood, J.T. 1992. Orchids of Costa Rica. Part 2. Icon. Pl. Trop. 15: pl. 1497 \& 1498.

Mora-Retana, Dora E. \& García, J.B. 1992. Lista actualizada de las orquídeas de Costa Rica (Orchidaceae). Brenesia 37: 79-124.

Pupulin, F. 2002. Catálogo revisado y anotado de las Orchidaceae de Costa Rica. Lankesteriana 4: 1-88.

Williams, N.H., Chase, M.W., Fulcher, T., \& Whitten, W.M. 2001. Molecular systematics of the Oncidiinae based on evidence from four DNA sequence regions: expanded circumscriptions of Cyrtochilum, Erycina, Otoglossum, and Trichocentrum and a new genus (Orchidaceae). Lindleyana 16(2): 113-139. 